\title{
Os lugares do crime: topografia criminal e imaginário social em Paris no século XIX
}

Dominique Kalifa*

\section{RESUMO}

Em Paris, como em vários outros lugares, os locais ocupam um lugar decisivo na apreensão das realidades e do imaginário do crime. No entanto, a cidade foi, ao longo do século XIX, o objeto de amplas transformações sociais e urbanas, sintetizadas pelos projetos de Haussmann, o que afetou profundamente a topografia do "vício" e da delinquência. Sáo essas evidências, os deslocamentos da violência e da criminalidade pelo espaço urbano, e especialmente a densidade dessa topografia, que este artigo procura analisar. Apoiado por um corpus essencialmente literário, formado por textos de grande difusão (romances, folhetins, crônicas parisienses, folhetos e materiais baratos) que dão tanta importância à questão do crime e que desempenham um papel decisivo na transmissão da memória dos lugares, este texto observa como o imaginário social se adapta a essas transformaçôes, bem como analisa a memória de lugares, com destaque para a forte autonomia das representaçóes de Paris.

Palavras-chave: imaginário social, literatura, violência.

\section{ABSTRACT}

In Paris as in other cities, "scenes" play an essential part in the appraisal of crime realities and crime imaginary. In the nineteenth century, the great social and urban changes that can be synthesized as haussmannisation deeply modified the topography of "vice" and delinquency in the capital. This article studies the evidence, the unwieldiness, and the shifting of that topography. Based on a corpus of widely distributed texts (feuilletons, dime and "popular" novels, Parisian columns, broadsheets), it shows how social imaginary adapted to the disruptions and played with the memory of places, pointing out the strong autonomy of Paris representations.

DOI - http://dx.doi.org/10.1590/2237-101X015028012

*Artigo originalmente publicado como: Les lieux du crime: topographie criminelle et imaginaire social à Paris au XIXe siècle. Sociétés \& Représentations, n. 17, p. 131-150, 2004/1. Uma primeira versão desse artigo foi publicada em inglês em French Historical Studies com o título "Crime scenes: criminal topography and social imaginary in nineteenth century Paris”, v. 27, n. 1, 2004. Tradução de Deivy Ferreira Carneiro.

"Professor de história contemporânea na Université Paris 1 Panthéon - Sorbonne e diretor da École doctorale d'histoire e do Centre d'histoire du XIXe siècle. Paris, França. E-mail: dominique.kalifa@univ-paris1.fr. 
Keywords: social imaginary; literature; violence.

Assim como os meios, as circunstâncias ou os autores do crime, os "lugares" desempenham um papel essencial na construção das realidades criminais. Ruas, praças ou becos: muitas vezes é na topografia urbana que se cristaliza o medo ou a obsessão do crime. Como sinalizou Balzac em Ferragus (1833), existem as ruas "assassinas", e a identidade dos lugares e dos não lugares do crime possui um lugar decisivo na expressão de insegurança. Mas esses lugares não se contentam apenas em causar medo; eles contribuem também para tornar o crime inteligível. A posição do cadáver, a localização de indícios e traços diversos ocupam uma função crescente nos procedimentos de investigação criminal do início do século XIX. Observamos então a multiplicação de esboços, de planos, de placas e de cortes; fontes de uma nova atenção topográfica que acelera a passagem para uma racionalidade judiciária. ${ }^{1}$ Ligando cada crime a seu ambiente e cada cadáver a seu cenário, as fotografias de identificação forense acentuam ainda mais esse processo no fim do século. Em torno dos lugares do crime se estabelece enfim uma última intriga, mais cultural e social. Muitas vezes investidos de significados pelos vizinhos ou familiares que ali chegam para comentar o que se passou; por vezes transformados em lugares de visitação ou até mesmo de peregrinação, ${ }^{2}$ eles desempenham um papel crucial na apropriação social do espaço. Preocupada, animada ou indignada, a memória da cidade moldada por esses lugares, e que mais tarde sustentará uma prolixa literatura criminal (folhetins, reclamaçôes ou causas célebres), revela-se muitas vezes uma operadora ativa de coesão e de solidariedade. ${ }^{3}$

Evidentemente, tal fenômeno encontra uma situação ideal na Paris do século XIX. Devemos nos perguntar aqui: como a capital, transformada pelo crescimento demográfico, pelas recomposiçóes sociais e pela agitação política, fez do crime uma das suas principais obsessôes? "Cada calçada de nossa boa cidade de Paris está vermelha”, escreveu em 1863 um

\footnotetext{
${ }^{1}$ Ver PORRET, Michel. La topographie judiciaire à Genève. Sociétés \& Rerésentations, n. 6, p. 191-209, 1998. Ver também: CHAUVAUD, Frédéric. Les Criminels du Poitou au XIXe siècle. Les monstres, les désespérés, les vouleurs. Poitiers: Geste Éditions, 1999.

${ }^{2}$ Assim como o "champ Langlois", onde o assassino Troppmann cometeu seus crimes em 1869, que se encontra investido de significados pelos vendedores ambulantes, pelos milhares de espectadores que visitam o local e imortalizado pelas fotografias. Ver: PERROT, Michelle. "L'affaire Troppmann", publicado inicialmente em 1981 e republicado em Les ombres de l'histoire. Crime et châtiment au XIXe siècle. Paris: Flammarion, 2001. p. 283-298.

${ }^{3}$ Refiro-me a este ponto em meu texto: "Crime, fait divers et culture populaire à la fin du XIXe siècle". Genèses. Sciences Sociales et Histoire, n. 19, p. 68-92, 1995. Ver também MAFFESOLI, Michel; PESSIN, Alain. La violence fondatrice. Paris: Éditions du Champ, 1978.

${ }^{4}$ Inauguradas pela obra fundadora de Louis Chavalier (Classes laborieuses et classes dangereuses à Paris pendant la première partie du XIXe siécle. Paris: Plon, 1958), essas questóes conheceram recentemente uma renovação. Ver principalmente: KALIFA, Dominique. L'encre te le sang. Récits de crimes et société à la Belle Époque.
} 
historiador da capital, ${ }^{5}$ resumindo adequadamente o sentimento geral. Ao mesmo tempo transgressão da norma, produção cultural e argumento político, o crime e a delinquência saturam o espaço público parisiense. Do interminável discurso social que resulta dessa situação, emerge uma geografia do "vício" e da periculosidade. São as evidências, a gravidade e os movimentos dessa topografia que este artigo pretende estudar. Porque o crime, como todas as outras atividades sociais, foi profundamente afetado pelo processo de haussmannização, que vasculhava e desafiava os locais tradicionalmente perigosos, onde atuavam os estranguladores. Sem dúvida a delinquência violenta, o "ataque noturno" ou o assassinato, dos quais trataremos aqui, constituem, em última análise, não mais que um aspecto marginal dos eventos criminais, mas que encarnam sua face visível; aquela que, tanto ontem como hoje, polariza os discursos e os temores. Gostaríamos então de discutir como a memória dos lugares se acomodou à formidável bulevarização que transformou a capital e como e com quais resistências as representaçóes do perigo foram pouco a pouco haussmannizadas. Apoiado por um corpus essencialmente literário, formado por textos de grande difusão (romances, folhetins, crônicas parisienses, folhetos e materiais baratos) que dão tanta importância à questáo do crime e que desempenham um papel decisivo na transmissão da memória dos lugares, este estudo topográfico gostaria de interrogar a surpreendente autonomia das representaçóes de Paris e a capacidade da "ville de papier" seguir o curso do seu próprio destino.

\section{Os teatros criminais da Paris romântica}

Inscritos numa tradição fortemente estabelecida, romancistas e cronistas da Monarquia de Julho assinalavam a esmagadora dominação criminosa do velho centro histórico e de suas margens adjacentes. O crime, principalmente na Île de la Cité, está "num emaranhado de ruas obscuras, estreitas, tortuosas que se estendem desde o Palais-de-Justice até a Notre-Dame". A convergência de representaçóes é absoluta e apresentam as antigas vielas da ilha, a rua des Cargaisons ou a rua du Marché Neuf, a rua de la Calandre, a rua aux Fèves ou o beco Saint-Martial como um "vasto Tribunal dos milagres", 7 onde não faltam ladróes, prostitutas e vagabundos. Esta reputação transborda da Cité propriamente dita até a margem direita do Sena, no perímetro dos Halles, entre o Palais-Royal e o Temple e, na margem esquerda, no bairro Montagne Sainte-Genevière, na praça Maubert, na rua Galandre e na

Paris: Fayard, 1995; CRAGIN, Thomas. Cultural continuity in modern France. The representation of crime in the popular press of nineteenth century Paris. Tese (Ph.D.) - Indiana University, 1996; DELATTRE, Simone. Les douze heures noire. La nuit à Paris au XIXe siècle. Paris: Albin Michel, 2000; SHAYA, Gregory K. Mayhem for moderns. The culture of sensationalism in France, c. 1900. Tese (Ph.D.) - University of Michigan, 2000; e DEMARTINI, Anne-Emmanuelle. L'affaire Lacenaire. Paris: Aubier, 2001.

${ }^{5}$ MAILLARD, Firmin. Le Gibet de Mautfaucon (étude sur le vieux Paris). Paris: Auguste Barby, 1863. p. 3.

${ }^{6}$ SUE, Eugène. Les mystères de Paris [1842]. Paris: Pauvert, 1963. p. 8.

${ }^{7}$ VIRMÂITRE, Charles. Paris qui s'efface. Paris: Savine, 1887. p. 71. 
rua Muffetard; lugares sinistros e perigosos, sempre retratados como antros de pilantras e trapaceiros. A estreiteza desse espaço permitia a paradoxal proximidade entre os lugares do crime e os da repressão. "Não é estranho, ou melhor, fatal que haja uma irreversível atração que faça sempre que estes criminosos gravitem em torno do formidável tribunal que os condena à prisão, ao trabalho forçado e ao cadafalso!", 8 nota maliciosamente Eugène Sue, que sabia, é claro, explorar o potencial romanesco dessas histórias. De um lado, antros, cabarés e redutos de malfeitores, cujas descriçôes tornaram-se rapidamente um dos virtuosismos de toda uma literatura criminal (o Lapin Blanc e o Paul Niquet, situados na rua aux Fèves; o Chat-noir, na rua de la Vieille Draperie; o Bordier, na rua Aubry-le-boucher; o Hôtel d'Anglaterre, na rua Saint-Honoré; o Épice-scié no bulevar du Temple; o Château-Rouge e o Pére-les-lunettes na rua Galande). Do outro lado, os principais órgãos da ordem: o Palais-de-Justice, a Conciergerie, a delegacia de polícia, cujo sórdido depósito se abria para a rua de Jérusalem, um "beco estreito, escuro e barrento onde o sol nunca penetra a não ser de forma dissimulada"; ${ }^{9}$ a sede da segurança pública, na rua Sainte-Anne; a praça de Grève, lugar de todas as execuçóes do Consulado em 1832, sem esquecer o necrotério, no cais do Marché-Neuf, assiduamente visitado pelos parisienses. Não muito longe dali, a prisão "de la Force", na rua do Roi-de-Sicile e a prisão de Sainte-Pélagie, acessível somente pela sinistra rua de la Clef e que acolhia a maioria dos detentos, com exceção das mulheres, enviadas ao convento das Madelonnettes, ${ }^{*}$ perto do Temple, antes da abertura de Saint-Lazare em 1834, na rua de faubourg Saint-Denis. Preciosa vizinhança em um tempo onde a estratégia policial consistia principalmente em se infiltrar no mundo do crime para neutralizá-lo.

Múltiplos fatores explicam essas localizaçôes. Sem romper com o modelo do Antigo Regime, o centro da capital, irrigado pelo Sena, continua ainda em 1840 a ser a Paris viva e popular, a Paris do trabalho, abarrotada, aquecida, entrelaçada de espaços de habitação, de trabalho, de distração, onde a violência da rua constituía um componente inerente à sociabilidade popular. ${ }^{10}$ As grandes mudanças demográficas e econômicas que se aceleraram na França da primeira metade do século XIX acentuaram esse fenômeno. Mais do que nunca, o centro da cidade tornou-se o lugar de aglomeração, de superlotação, de miséria material e moral - portanto, do crime, fato este que os observadores sociais descreviam incansavelmente. Mas a preocupação com o pitoresco tem também um papel, para muitos, na construção desse enfoque excessivo: trata-se da memória dos assassinos medievais e dos Tribunais de Milagres, ${ }^{* *}$ estando o maior destes "situado em um dos bairros mais sujos, mais remotos

\footnotetext{
${ }^{8}$ SUE, Eugène. Les mystères de Paris, op. cit. p. 8.

${ }^{9}$ DUMAS, Alexandre. Les mohicans de Paris [1854-1859]. Paris: Gallimard, 1998. p. 246.

${ }^{*}$ Convertido em prisão a partir de 1793. (N.T.)

${ }^{10}$ Ver para os períodos precedentes: FARGE, Arlette; ZYSBERG, André. Les théâtres de la violence à Paris au XVIIIe siècle. Annales ESC, n. 5, p. 984-1015, 1979. Ver Também PEVERI, Patrice. Les pickpockets à Paris au XVIIIe siècle. Revue d'Histoire Moderne et Contemporaine. n. 29-1, p. 150-173, 1982.

** Em francês, "Cours de Miracles". Termo utilizado na França para caracterizar os bairros miseráveis de Paris, ou as ruelas sujas, barrentas e sombrias onde os migrantes rurais desempregados e pobres se juntavam, por falta de condiçôes, aos indivíduos de conduta suspeita ou criminosa. (N.T.)
} 
e mais mal concebidos da cidade de Paris, entre a rua Montorgueil, o convento des Filles-Dieu e a rua Neuve-Saint-Sauveur". ${ }^{11}$ Aos olhos de numerosos contemporâneos, a Paris da Monarquia de Julho tendia "a se tornar aquela da Idade Média, com suas emboscadas, com seus assassinatos de becos". ${ }^{12}$

Presente tanto na imprensa quanto nas enquetes sociais e nas fisiologias dos romances de folhetins, estas representaçóes construíram um modelo coerente e persistente, que fez da Île de la Cité e de suas margens um espaço quase natural do crime. Capital do século XIX, Paris consolida essas imagens aterradoras tanto aos olhos de observadores estrangeiros quanto aos olhos de sua estarrecida província. Não é nessa Paris que Edgar Poe situa a ação de três célebres histórias que inauguram a narrativa da detecção? ${ }^{13}$ Se o cavaleiro Dupin* continua na "rua Dunot, n. 33, terceiro andar, faubourg Saint Germain"; a rua Morgue se situa bem no coração da velha Paris criminal: "É uma das miseráveis passagens que liga a rua Richilieu à rua Saint-Roch"; Marie Roget mora na rua Pavée Sanit-André e trabalha com um perfumista do Palais-Royal. Por mais fantasiosa que seja ("Eu preciso advertir a propósito da rua Morgue, da passagem Lamartine etc., que Edgar Poe nunca veio à Paris”, escreveu Baudelaire), ${ }^{14}$ esta topografia salienta a importância da Paris pré-haussmanniana no imaginário criminal do século XIX.

No entanto, nesta primeira metade do século XIX, é perceptível um primeiro e duplo deslocamento, que abandona pouco a pouco os espaços abarrotados do centro. Presente no transcorrer de um longo período, ${ }^{15}$ a transferência para além das bordas dos espaços da periculosidade urbana tornou-se mais intensa durante a Monarquia de Julho. Em direção norte, onde os bairros de Porcherons e de la Courtille são percebidos como lugares inseguros desde o século XVIII, ${ }^{16}$ são relatados inúmeros bolsões de violência: o canal Saint-Martin e os terrenos baldios que o circundam, onde bandos de desordeiros jogam suas vítimas nas águas do mesmo; Belleville, Ménilmontant e a barreira du Combat, covil de inúmeros malfeitores. "Era lá seu quartel general, onde eles estavam constantemente em massa e onde a desgraça os viria encontrar" ${ }^{\prime \prime}$, escreveu Vidocq em suas Mémoires. Antigo local de enforcamento, um vasto espaço espremido entre o bulevar e a la Butte Chaumot, o Montfaucon, que servia às vezes de local de despejo e de esgoto, era ainda percebido como um lugar de

\footnotetext{
${ }^{11}$ SAUVAL, Henri. Histoire et recherche des antiquités de la ville de Paris. Paris: Moette, 1724.

${ }^{12}$ La Chronique de Paris, 18 oct. 1836. Citado por DEMARTINI, Anne-Emmanuelle. L'affaire Lacenaire, op. cit. p. 150.

${ }^{13}$ The murders in the rue Morgue (1841), The purloined letter (1842), The mystery of Marie Roget (1850).

* Detetive criado por Edgar Allan Poe que aparece pela primeira vez na obra Os assassinatos da rua Morgue e figura nas três obras citadas na nota acima. (N.T.)

${ }^{14}$ Ver BENJAMIN, Walter. Le Paris du Second Empire chez Charles Baudelaire [1938]. Paris: Payot, 1979.

${ }^{15}$ Ver GEREMEK, Bronislaw. Les marginaux parisiense aux XIVe et XVe siécles. Paris: Flammarion, 1976. Ver também: MERRIMAN, John M. The margins of the city life. Explorations on the French Urban Frontier, 1815-1851. Nova York: Oxford University Press, 1991.

${ }^{16}$ FARGE, Arlette; ZYSBERG, André. Les théâtres de la violence à Paris au XVIIIe siècle, op. cit.

${ }^{17}$ VIDOCQ, Eugène François. Mémoires [1828]. Paris: Laffont, 1998. p. 293.
} 
grande periculosidade. Mas é sobretudo para além das bordas periféricas do sul que as representaçóes, especialmente as literárias, se movem. Altamente simbólica, a decisão tomada em 1832 de deslocar a guilhotina da praça de Grève para a barrière Saint-Jacques acompanha esse movimento. Os bairros que formavam o então décimo segundo distrito* (Saint-Marcel, Saint-Jacques, L'Observatoire) estavam entre os mais pobres da capital. Covis de trapaceiros, verdadeiros "antros de infecção", de acordo com Alexandre Parent-Duchâtelet, eles formavam sinistros bolsóes de violência. Foi lá, na rua Croulebarbe, no lugar conhecido como campo de l'Alouette, que o jovem Ulbach assassinou a pastora de Ivry, em maio de 1827, gerando um célebre fait diver. Também considerada perigosa era a barrière d'Italie, de onde se seguia para os subúrbios do sul, bem como Bicêtre, situada uma milha no caminho para Fontainebleau, onde os condenados a morte esperavam o dia de sua execução; e também o cemitério de Ivry, no qual se enterravam os sentenciados a morte.

A identidade criminal que tornava esses bairros locais excêntricos deve muito à literatura. Se é na rua aux Féves que tem início o livro Os mistérios de Paris, é na barrière Saint-Jacques que ele tem sua conclusáo, assinalando o vigor dessa transferência espacial. Observamos o mesmo n'Os moicanos de Paris de Alexandre Dumas, profundamente enraizado no bairro de Saint-Jacques e, sobretudo Os miseráveis, de Victor Hugo, verdadeiro romance dessas bordas do sul; Italie, Gobelins ou d'Enfer. É no bulevar de L'Hôpital que se encontra o casebre Gorbeau $^{* *}$ e é "nas estepes adjacentes à Salpêtrière" que atua, durante a noite, o bando de Patron-Minette.

Mas a esse deslocamento topográfico soma-se outro movimento, verticalizado, que mergulha fundo nas entranhas da capital, até as pedreiras, as catacumbas e os esgotos. Os fornos de gesso de Clichy, as pedreiras de Montmartre ou d'Amérique na margem direita do Sena; a imensa escavaçáo que se estende, na margem esquerda, de Grenelle e Montrouge até os Jardin des Plantes, formam, de acordo com alguns, um verdadeiro país subterrâneo, criminoso por natureza, que qualquer um acessa por uma das numerosas escadas situadas em Val-de-Grâce, na borda do Maine, na Puits-qui-parle ou ainda na praça d'Enfer. Recusada na temática tradicional do submundo ${ }^{* * *}$ ou naquela metáfora hugoliana das "partes inferiores" e da caverna social, a existência de uma imensa Paris subterrânea e criminal constitui, portanto, um clichê generalizado que romancistas populares como Élie Berchet ou Pierre Zaconne encarregaram-se de espalhar. ${ }^{18}$

\footnotetext{
No original: XIIème arrondissement. Optamos por traduzir o termo arrondissement por distrito e o termo quartier por bairro. (N.T.)

${ }^{* *}$ Local de suma importância na obra Os miseráveis, de Victor Hugo. (N.T.)

*** O termo utilizado pelo autor é bas-fonds, sem tradução adequada para o português, mas que pode significar algo próximo daquilo que entendemos em português por submundo; lugar do populacho onde reina a miséria e a criminalidade. Sempre que o termo submundo aparecer no texto refere-se então a este conceito de bas-fond. (N.T.)

${ }^{18}$ BERTHET, Élie. Les catacombes de Paris. 1854; ZACCONE, Pierre. Les Dames des catacombes. Paris: Ballay Ainé, 1863; IMBERT, Pierre-Léonce. Les catacombes de Paris. Paris: Librarie international, 1867; Les
} 


\section{Deslocamento, recuo, retrocesso}

Bulevarizando a topografia, a sociologia e a economia da capital, a haussmannização evidentemente muda toda a cidade. Se as ambiçôes atreladas a esse processo não dizem respeito explicitamente à delinquência, elas buscam, entretanto, a redução de uma "crise" e a diminuição das disfunçóes urbanas, entre as quais a criminalidade, que, nesse momento, anda lado a lado com o medo social. A destruiçáo dos cortiços que margeavam a Notre-Dame, os novos avanços e a anexação dos distritos suburbanos são entendidos imediatamente pelos contemporâneos como eventos de uma importância capital para percepção da localização do risco criminal. Uma nova cartografia da delinquência emana daí e recebe rapidamente o suporte das representaçôes literárias. As inflexôes da topografia criminal que registram então os romancistas e cronistas constituem uma série de movimentos desordenados, às vezes contraditórios, mas cuja evolução desenha, ao longo de meio século, uma trajetória finalmente coerente que podemos resumir nas três figuras entrelaçadas do deslocamento, do recuo e, então, do retrocesso.

Acompanhando o movimento da haussmannização, a primeira figura é a mais evidente. A destruição da Cité é uma realidade da qual os romancistas e cronistas tomam ciência imediatamente. $\mathrm{O}$ próprio Haussmann conseguiu especificar essa questão na sua própria ação: "Desmantelando os antigos tijolos, desembaraçando a marretadas estes novelos de ruas insalubres, fazendo o ar e o sol penetrá-las violentamente, não trazemos apenas a salubridade; moralizamos estes bairros miseráveis, pois perseguimos os malfeitores neste grande dia de terror e eles não mais se esconderão nestes vastos espaços onde antes ficavam seus barracos deteriorados", declara ele diante do conselho municipal. ${ }^{19}$ A partir da década de 1860, multiplicam-se os textos que assinalam os feitos desses trabalhos sobre a criminalidade: "O métier de assassino torna-se a cada dia mais e mais impraticável e os gatunos começam a se expatriar", escreveu Alfred Delveau em 1862. ${ }^{20}$ Mais comedido, du Champ escreve alguns anos mais tarde: "O próprio desenvolvimento da cidade coloca obstáculos aos delitos das pessoas desagradáveis que abundam entre nós”. ${ }^{21}$ A destruição da velha Paris necrosada pelo crime se deu de uma forma tão proveitosa que permitiu reviver as imagens do submundo. "A Cité, a hedionda Cité, desmantelada pelas picaretas dos demolidores, viu desaparecer com ela suas redes de ruelas infames, de casebres desprezíveis, onde fervilhava uma população

Mémoires de M. Claude, chef de la police de sûreté sous le Second Empire (1881) evoca uma outra rede "criminal" subterrânea, situada entre a barrière des Bonshommes e os hauteurs du Trocadéro. (reed. Club Français du Livre, 1962. p. 57)

${ }^{19}$ Declaração do prefeito Haussmann diante do conselho municipal de Paris. Citado por LEMOINE, Yves. Paris sur crime. L'impossible histoire. Paris: Jacques Bertoin, 1993. p. 131-132.

${ }^{20}$ DELVEAU, Alfred. Histoire anecdotique des cafés et cabarets de Paris. Paris: Dentu, 1862. p. 100. Citado por DELATTRE, Simone. Les douze heures noires, op. cit. p. 510.

${ }^{21}$ DU CHAMP, Maxime. Paris. Ses organes, ses fonctions et sa vie dans la second moitié du XIXe siècle. Paris: Hachette, 1872. v. 1, p. 427. 
imunda. A rua aux Fers e o cabaré Lapin Blanc não existem mais, o Tribunal dos Milagres não passa de uma lenda”, escreveu neste sentido o jornalista e folhetinista Georges Grison. ${ }^{22}$

Deslocada assim do coração da capital, a periculosidade criminal vai, a partir de então, se ancorar em dois novos espaços. O primeiro deles é formado por aquilo que Ponson du Terrail chama de "novos bairros", que compreendem os distritos estendidos a oeste e a noroeste parisiense e que resultaram dos trabalhos de Haussmann. "Os crimes se adaptam com vertiginosa velocidade no lado oeste de Paris", nota o antigo chefe de segurança Gustave Macé. ${ }^{23}$ Ao "austero faubourg Saint-Germain" símbolo até então de belos bairros sempre ameaçados por algum complô criminal, se sobrepóem pouco a pouco os luxuosos hotéis do oitavo e nono distrito (Paul Féval, Les habits noirs, 1865) ${ }^{24}$, a Madeleine e a estrada d'Antin, a rua de la Pompe e os Champs-Élysées, Montmartre e "os novos bulevares" (Ponson du Terrail, Les dames de Paris, 1857-1870). O romance judicial, que floresceu depois de 1870, fez parte igualmente dessas novas topografias. Émile Gaboriau nos fornece alguns exemplos. M. Lecoq, seu detetive, mora na "rua Montmartre, n....", e suas investigaçóes o levam à Saint-Lazare, no décimo terceiro distrito, ou até Batignolles, onde foi assassinado o aposentado Pigaureau. ${ }^{25}$ Do Drame de la rue de la paix (Adolphe Belot, 1875) ao Crime de l'opéra (Fortuné du Boisgobery, 1879) e também ao Mystère d'Auteuil (Jules de Gastyne, 1904), praticamente não resta nenhum bairro desta nova Paris que escape da atenção dos romancistas. O espaço situado entre La Concorde e Le Bois se torna um dos lugares principais do romance criminal, e também não é muito perspicaz andar à noite entre o Sena e l'Étoile: "Os ladróes podiam atuar nesses espaços mais tranquilamente que na floresta de Bondy", escreveu Boisgobery. ${ }^{26}$ Emancipam-se igualmente os órgãos ligados às novas funçôes da cidade haussmanniana, estaçóes de trem e hipódromos, onde atuam desenfreadamente os batedores de carteira; os bosques de Boulogne e de Vincennes, abarrotada de assediadores e, é claro, o metrô, rapidamente transformado em teatro de novas violências. ${ }^{27}$

Esse mesmo desencanto do antigo centro atinge também os bairros novos que se desenvolvem na periferia leste e sul parisiense. "O mundo dos ladrôes passou em massa para o lado das antigas bordas, para bairros recentemente anexados e que parecem não ter nada além de uma ligação administrativa com a antiga Paris”, escreveu du Camp em 1872. ${ }^{28}$ Mas entre esses novos espaços do crime e da delinquência se estabelece uma hierarquia. Os bairros densos do cinturão operário como Ménilmontant, Belleville, Bercy ou la Butte-aux-cailles são descritos com cada vez mais frequência como lugares de desvio e violência, como bem

\footnotetext{
${ }^{22}$ GRISON, Georges. Paris horrible et Paris original. Paris: Dentu, 1882. p. 1.

${ }^{23}$ MACÉ, Gustave. Crimes impunis. Paris: Dentu, 1882. p.1.

${ }^{24}$ LELIONNAIS, François. Le Paris des habits noirs. Le Magazine Littéraire, p. 58-64, out. 1972.

${ }^{25}$ GABORIAU, Émile. L’affaire Lerouge. Paris: Dentu, 1866; Monsieur Lecoq. Paris: Dentu, 1867 e Le petit vieux des Batignolles. Paris: Dentu, 1870.

${ }^{26}$ BOISGOBERY, Fortuné du. Le coup d'oeil du monsieur Piédouche [1883]. Paris: Rivages, 1999. p. 36.

${ }^{27}$ SALLES, Pierre. Le crime du métro, folhetim publicado no La Petite République, jun./set. 1912.

${ }^{28}$ DU CAMP, Maxine. Paris, op. cit. v. 3, p. 55.
} 
afirmam os refrãos das cançóes "realistas". A respeito de Montmartre se constrói uma representação específica onde o crime está em parte ligado ao mundo das letras e das artes. ${ }^{29}$ É preciso também levar em conta a Bastille, marcada pela sinistra presença da rotatória de la Roquette, onde desde 1852 está instalada a guilhotina, trancada em um galpão da rua de la Folie-Régnault; outro ponto de aglomeração frequentemente evocado. Mais abaixo, próximo à rua Sainte-Marguerite, encontra-se a Paris dos migrantes da regiáo de Auvergne, mas também o local de prostituição e de danças, onde triunfam as tavernas La Boule Rouge ou Gravilliers, "um reduto de pilantras e aproveitadores". 30

Mas nesta segunda metade do século XIX o momento não é mais das "classes perigosas”, e é nas suas margens, tanto sociais quanto geográficas, que a Paris operária se revela criminosa. Os espaços mais sinistros são aqueles que margeiam os bulevares exteriores: la Villette, la Chapelle ou o décimo quinto distrito, próximo a Saint-Charles, Javel ou Grenelle, locais "sombrios, propícios a emboscadas que dão a sensação de um lugar de vício e de crime". ${ }^{31}$ Nas proximidades dos bulevares exteriores e nos entornos das fortificações a ameaça se intensifica, como se as muralhas fossem utilizadas para deter e impedir o inimigo interior. Entre o caminho de ferro do pequeno cinturão e as muralhas se estendem de fato espaços inquietantes, marcados por uma violência mais consolidada que em outros lugares. Os bandidos e as garotas que perambulam à noite nessas regióes desertas estão entre os piores da capital. "É ao lado das fortificaçóes que não vemos pessoas descentes", canta Bruant. ${ }^{32}$ Certos cantos são mais sinistros do que outros: o bulevar Lannes, o bulevar Berthier e toda a região que se estende de Clichy a Bagnolet. Mas o verdadeiro perigo está ao sul, próximo de Gentilly, Châtillon ou perto de berges du Point du Jour, em Billancourt, "onde não era possível aventurar-se sem estar armados" ${ }^{33}$

Do outro lado das muralhas, as representaçóes são mais sutis. Emaranhado de barracos e esconderijos, de terrenos baldios e também de galinheiros, a "zona" é um lugar mais pitoresco que perigoso, que passa a ser retratado de uma forma bastante benevolente por toda uma literatura das margens. ${ }^{34}$ Quanto às comunas vizinhas, elas veem sua imagem se degradar pouco a pouco. O espetacular sucesso que conheceu o crime de Pantin em 1869 chegou de fato a ampliar a forte identidade criminal dos subúrbios. São descritos por sua periculosidade, sobretudo devido à insuficiência de policiais que aparecem apenas para deter os vagabundos e proibir a permanência destes no local. Certos lugares do norte e do leste parisiense, como Clichy, Les Lilas, Bagnolet, também adquirem uma sinistra reputação. Os

${ }^{29}$ Ver CHAVALIER, Louis. Montmartre du plaisir et du crime. Paris: Laffont, 1981; SEIGEL, Jerrold. Bohemian Paris. Culture, politics and the boundaries of bourgeois life, 1830-1890. Nova York: 1986.

${ }^{30}$ LORRAIN, Jean. La maison Philibert [1904]. Paris: Christian Pirot, 1992. p. 116.

${ }^{31}$ SOUVESTRE, Pierre; ALLAIN, Marcel. L'arrestation de Fantômas. Paris: Fayard, 1912. p. 275.

32 "À Saint-Ouen", coletado no volume Dans la rue, Paris, 1889.

${ }^{33}$ SOUVESTRE, Pierre; ALLAIN, Marcel. L'arrestation de Fantômas, op. cit. p. 259.

${ }^{34}$ Por exemplo HIRSCH, Charles-Henri. Le tigre et coquelicot. Roman de fortifs et des boulevards. Paris: Librairie universelle, 1905; e MACHARD, Alfred. L'épopée au faubourg. Paris: Mercure de France. 
Outre-fortifs" "são locais vermelhos, nos quais se sente a morte e o sangue", escreveu em 1904 Delphi-Fabrice, cujas Impressions de banlieue se equiparam a "Pantin-le-Raisiné" ou a "Vincennes-la-Cabriole". ${ }^{35}$ Mas essas percepçóes são tardias, raras antes da Belle Époque, figurando apenas em obras breves e fugazes.

Pois, para os romancistas de folhetim e os cronistas, o essencial está em outro lugar. Um movimento estranho e paradoxal de reorientação acompanha esses deslocamentos evocados até aqui. Mesmo toda a destruição e remodelaçáo pela qual passaram a Cité e a velha área do crime no centro da cidade não foram suficientes para impedir sua retomada por seus antigos habitantes: assassinos, prostitutas e cafetóes. "Logo que os grandes bulevares, as ruas largas, as praças e casas magníficas foram construídas, canalhas de todas as espécies, portadores de instintos selvagens próximos aos dos animais que facilmente encontram seus covis, retomaram rapidamente todos os cortiços que permaneceram de pé”, escreveu Gustave Aimard. ${ }^{36}$ Para a maior parte das narrativas populares ou pitorescas que relatam a delinquência parisiense, esse retorno às origens é geral. Os Halles e suas "ruelas insalubres"; as proximidades do Temple, de Saint-Merri e de Arts-et-Métiers; os cortiços de la Cour de Rome ou da praça Maubert reocupam então o centro das representações. Com algumas nuances, é a Paris de Sue e de Frégier que ressurge sobre a Paris de Haussmann. Ao longo da Belle Époque, é ainda o Halles (bulevar Sébastopol, os bairros des Innocents du Temple ou des Innocents) que forma o epicentro da Paris-Apache.* Alguns raros autores se dão ao trabalho de denunciar essas representaçóes anacrônicas: "os ladróes vêm dos bairros periféricos de Grenelle, Montrouge, Clichy e Belleville. Eles não têm mais seus covis aqui. Esta é uma grande piada que nos querem fazer acreditar. O Caveau des Halles, o Père Lunette, o Pére Jules, o Château Rouge são hoje cabarés inofensivos". Mas a maioria se esforçava para justificar esse fenômeno: "se o perigo se modificou, não podemos dizer que ele desapareceu totalmente", explica Pierre Zaccone. ${ }^{37}$ "Muitas ruas insalubres e condenadas permaneceram intocadas, e foram conservadas sem razóes plausíveis", ${ }^{8}$ acrescenta Gustave Aimard. Denunciar essas "ruas crapulosas", tais como a rua des Anglais, "resquício dessa velha Paris que permaneceu de pé após as demoliçôes e transformaçóes", 39 constitui um reflexo natural para muitos observadores. Novas "cidades de maltrapilhos" surgiram a dois passos das antigas. ${ }^{40}$ Alguns se esforçavam

\footnotetext{
*Antigas fortificações parisienses que, após sua demolição em meados do século XIX, foram transformadas em cortiços pela população depauperada. (N.T.)

${ }^{35}$ DELPHI-FABRICE. Outre-fortifs. Paris: Malot, 1904.

${ }^{36}$ AIMARD, Gustave. Les peaux-rouges de Paris. Paris: Dentu, 1888. p. 260.

${ }^{* *}$ Paris-Apache é um termo empregado para descrever a capital francesa no final do século XIX e início do $\mathrm{XX}$, tomada por gangues de jovens que aterrorizavam o imaginário da boa sociedade. Apache era o termo utilizado para descrever tais gangues. (N.T.)

${ }^{37}$ ZACCONE, Pierre. Les nuits du boulebard. Paris: Dentu, 1876. Citado por DELATTRE, Simone. Les douze heures noires, op. cit. p. 527.

${ }^{38}$ AIMARD, Gustave. Les peaux-rouges de Paris, op. cit. p. 260.

${ }^{39}$ WOLF, A. Mémoires d'un parisien. L'écume de Paris. Paris: s.n., s.d. p. 38.

${ }^{40}$ E também "cité des singes", apresentado por Pierre Delcourt, L'Agence Taboureau. Paris: Rouff, 1881.
} 
para denunciar qualquer edifício que havia escapado das picaretas dos demolidores, onde "o crime espreita e se abriga" ${ }^{41}$ Desse modo "o conjunto de casas localizadas entre o bulevar Saint-Germain e o cais de Montebello abriga ainda alguns espécimes curiosos dos velhos pilantras de outrora". ${ }^{42}$ Celebra-se o Lapin Blanc e o Paul Niquet, ${ }^{43}$ e todos aqueles antigos cabarés que permaneceram de pé ou foram reconstruídos. Tais locais foram promovidos a pontos centrais do turismo parisiense pela famosa Tournée des Grands Ducs, apontados pelos guias, ${ }^{44}$ ou revisitados pela literatura, como o Château Rouge da rua Galandre. ${ }^{45}$

A esta resistência ao velho centro da cidade soma-se aquela de alguns outros espaços tradicionais de representação: o canal Saint-Martin, já apaziguado, mas que continuava a inspirar os romancistas, assim como o Carrières d'Amériques e seus velhos esconderijos de vagabundos, situados perto de Montfaucon. Transpassados por novas artérias, metade delas cobertas pelo parque Buttes Chaumont, esses esconderijos "perdiam a cada dia a fisionomia que sua triste fama lhes deu" e o ataque noturno não fazia mais suas vítimas, escreveu um cronista em 1876. ${ }^{46}$ Mas tal fato pouco importava aos romancistas que continuavam a povoar tais locais com sinistros bandidos. ${ }^{47} \mathrm{O}$ mesmo vale para a Paris subterrânea das catacumbas e dos esgotos, indispensável a toda representação da delinquência. Tal representaçáo também servia para alimentar o estereótipo de uma nação clandestina e da contrassociedade do submundo. Eram então nos esgotos da Cité que sempre se reuniam à noite os bandos de assassinos e andarilhos; ${ }^{48}$ nos seus labirintos que os gênios do crime, tais como Zigomar ou Fantômas, organizavam seus complôs ou torturavam seus prisioneiros; era lá que prosperavam os estranhos clãs criminosos, como os "talpas", os “japistes" ou os "Grouilleurs". 4 Entre o centro e o submundo estabelecia-se uma relação de natureza orgânica. Esse "mundo subterrâneo" não sobreviveria, de fato, se prejudicasse o coração da cidade; e o submundo, com seus cabarés e bordéis, é nada mais do que o outro lado da moeda; essa é a contradição sobre a qual se fez Paris.

\footnotetext{
${ }^{41}$ DU CAMP, Maxime. Paris, op. cit. v. 3, p. 52.

${ }^{42}$ Ibid., p. 59.

${ }^{43}$ La Maison du Lapin Blanc et les boulettes du Lapin-Blanc. Paris: Chez Mauras, 1859.

* Referência às viagens de diversão dos grandes duques russos a Paris no final do século XIX e início do XX. (N.T.)

${ }^{44}$ Cortiços e pocilgas são assinalados pelo Guide des plaisirs de la nuit, 1905; ou pelo Dictionnaire géographique et administratif de la France de Paul Joanne (Hachete, 1899, t. 5). Ver a este respeito: CSERGO, Julia. Dualité de la nuit, duplicité de la ville. Sociétés \& Représentations, n. 4, p. 105-120, 1997.

45 GORON, Françóis-Marie (Dir.). L'amour à Paris. Paris: Flammarion, s.d. t. 4.; ou LORRAIN, Jean. Contes d'un buveur d'éther. Paris: Ouendorf, 1900.

${ }^{46}$ IMBERT, Pierre Léonce. À travers Paris inconnu. Paris: Georges Decaux éditeur, 1876. p. 252.

${ }^{47}$ LABOURIEU, Théodore. Les Carrières d'Amérique. Le Journal de Dimanche, abr. 1879.

${ }^{48}$ GUÉROULT, Constant et COUDEUR, Pierre de. Les etrangleurs de Paris. Paris: Chappe, 1859.

${ }^{49}$ LEROUX, Gaston. La double vie de Théophraste Longuet. Paris: Flammarion, 1904; SOUVESTRE, Pierre; ALLAIN, Marcel. Le bouquet tragique. Paris: Fayard, 1912; Le voleur d'or. Paris: Fayard, 1913.
} 
De fato, tudo se passava como se os romancistas, incapazes de emancipar-se desses lugares que assombravam o imaginário do crime, acabassem por se dedicar a reinventar tais locais sem cessar. Esse excesso de representaçôes se tornou muito estereotipado, mas mesmo assim sua relação com o real tendia a aumentar. Essas mesmas se instalam sobretudo na temporalidade, alimentando um imaginário que cruzou o limiar do século XX. Em 1927, Pierre Mac Orlan retorna à história já batida e recontada mais de uma centena de vezes do Lapin Blanc, dos cortiços e dos covis de bandidos, ${ }^{50}$ ao passo que repórteres e romancistas continuavam a divulgar a mesma imagem do centro de Paris, "os bares horríveis da rua Simon-le-Franc ou da rua Aubry-le-boucher". Eis aqui, a título de exemplo, como Guy de Téramond apresenta, em 1929, alguns bairros do centro:

Em pleno dia, mesmo sob o sol reconfortante, a rua Brise-Miche, a rua Simon-le-Franc ou algumas partes da rua Quincampoix já apresentam uma hedionda e assustadora imagem onde o perigo espreita em cada buraco tenebroso aberto em tijolos pegajosos, de onde ouvimos gritos, risadas, falatório; de onde sentimos o odor de álcool no ar e sentimos a possibilidade eminente de uma emboscada.

A noite e o nevoeiro surgem e pensamos se dessa fossa abominável a vadiagem, com seus trapos, orgias e crimes, não havia se espalhado pelas redondezas. O sinistro bando de la Coquille cujo líder canta suas façanhas; os batedores de carteira, os assassinos, os rufiōes, os bruxos e os bandidos de outrora se achavam à vontade nessas ruelas que pouco haviam mudado ao longo do tempo, nas quais os sentinelas do rei colocaram para correr um sombrio exército do crime apenas diferente do de hoje, nesse submundo onde relutamos em acreditar que ainda podem respirar e viver seres que têm algo de humano. ${ }^{51}$

Tais descriçóes, onde o espaço e o tempo parecem transcorrer para celebrar "o charme mórbido da velha Paris", ${ }^{52}$ não estão isoladas. Nós as encontramos frequentemente no período entre guerras, sob a pena dos cronistas e repórteres, ${ }^{53}$ descritas como se nenhuma encenação da Paris delinquente ou desviante fosse capaz de se livrar dessas representaçôes anacrônicas.

Sem dúvidas, não se pode exagerar a importância desse recuo que, como vimos, saturou o imaginário topográfico do crime. Ela, no entanto permaneceu viva e não desapareceu de fato até o êxito da terceira inflexão, que podemos qualificar como retrocesso. O melhor exemplo sobre isso pode ser fornecido pela série Fantômas (1911-1913), esse surpreendente romance de mais de doze mil páginas, cujo essencial náo foi escrito, mas gravado pelos autores,

\footnotetext{
${ }^{50}$ ORLAN, Pierre Mac. Nuits aux bouges. Paris: Flammarion, 1929.

${ }^{51}$ TÉRAMOND, Guy de. Les bas-fonds. Paris: Ferenzi, 1929. p. 142.

${ }^{52}$ PYAT, Félix; MORPHY, Michel. Le chiffonnier de Paris. Paris: Fayard, 1887. p. 12.

${ }^{53}$ Dois exemplos podem ser citados, dentre outros: CHAMPSAUR, Félicien. L'empereur des pauvres. Épopée sociale en six époques. Paris: Ferenczi, 1922; e LE FÈVRE, Georges. Je suis un gueux. Paris: Baudinière, 1929.
} 
em um tipo de operação de escrita automática onde transparece toda a doxa do imaginário da Belle Époque. ${ }^{54}$ Se essa versão moderna dos Tableaux de Paris não ignora nenhum recanto da capital, ela privilegia, todavia, os espaços urbanos anexados nos anos 1860, observando as novas topografias parisienses. ${ }^{55} \mathrm{O}$ deslocamento dos bons bairros em direção a oeste é geral: é entre la Concorde e le Bois que reside, daí em diante, a Paris chique e abastada. Quanto à Paris delinquente, como exceção de alguns locais tradicionais destinados a mostrar que o cordão umbilical não foi rompido, ela se dirige quase que inteiramente em direção à periferia (Montmartre, Belleville, La Chapelle, La Villete Bercy, Grenelle) e muitas vezes para além das fortificações, rumo a Saint-Ouen, Châtillon, Bagneux etc. Mais precisamente, este deslocamento é excessivo; quase suspeito. Ele revela, é claro, os movimentos reais da sociologia parisiense, mas assinala sobretudo uma realidade simbólica: se a Cité não é mais Paris, então Paris não é mais nada, sobretudo o centro do mundo que a cidade encarnou ao longo de todo o século XIX. ${ }^{56}$ Por meio deste processo radical de afastamento do centro se liga um tipo de descapitalização do espaço parisiense, que parece perder sua substância e sua supremacia. Toda uma série assinala essa situação: desloca-se entáo de um universo monocêntrico em direção a um mundo notadamente policêntrico. Telégrafo, telefone, TSF, navios e transcontinentais fazem de Fantômas um grande viajante que percorre a Escócia, a Rússia, o México, a Colômbia, Natal etc. Paris, portanto, não é mais este centro absoluto e sonhado: a cidade se dilui num espaço mundializado, ameaçada sobretudo pela emergência de novos centros. Porque a série, exemplar por muitas razóes, indica também a crescente importância de um novo centro, os Estados Unidos, cujo imaginário impregna o romance: bilionários e detetives, boxeadores e "Tios da América", circo Barzun e a estética serial, de acordo com Nick Carter. A ideia, a propósito, estava no ar há muito tempo: a haussmannização traz nela mesma a americanização de Paris e o "ianqueísmo".57

\section{Restriçóes sociais, restriçóes narrativas}

Esse complexo vaivém dos locais do crime não se explica a não ser por múltiplas razóes. Em primeiro lugar, é preciso refletir a respeito das práticas efetivas da delinquência parisien-

\footnotetext{
${ }^{4}$ Sobre a importância de Fantômas no imaginário parisiense ver: Fantômas. Europe, n. 590-591, 1978; KALIFA, Dominique (Dir.). Nouvelle revue des études fantômassiennes. Paris: Joëlle Losfeld, 1993; WALZ, Robin. Pulp surrealism. insolent popular culture in early twentieth-century Paris. Berkeley: University of California Press, 2000.

${ }^{55}$ Ver VAREILLE, Jean Claude. Le Paris de Fantômas: du pittoresque à l'inquiétant. Nouvelle Revue des Etudes Fantômassiennes, Paris, p. 69-94, 1993.

${ }^{56}$ BENJAMIN, Walter. Paris, capitale du XIXe siècle. Le livre des passages. Paris: Le Clerf, 1989. Ver também as atas do colóquio Paris au XIXe siècle. Aspects d’um mythe littéraire. Lyon: Presses universitaires de Lyon, 1984.

${ }^{57}$ Sobre estes pontos ver: BERNARD, Jean-Pierre A. Les deux Paris. Les représentations de Paris dans la seconde moitié du XIXe siècle. Paris: Champ Vallon, 2001. p. 217-219.
} 
se. Mesmo as representaçóes literárias sendo incapazes de retratar o "real", elas registram, talvez de uma maneira mecânica ou involuntária, os fenômenos objetivos. Esse processo amplo de saída e retorno da criminalidade em direção ao centro da cidade coexiste ao longo da segunda metade do século XIX. Sem dúvida, o fenômeno principal foi a transferência da delinquência em direção à periferia. Esvaziando o velho centro industrial dos tipos mais pobres e suspeitos, ${ }^{58}$ a haussmannização concentrou nas margens da cidade os elementos mais instáveis e mais violentos das classes populares e acabou por acelerar um processo iniciado há algum tempo. ${ }^{59}$ Estudando os domicílios dos indivíduos processados pela corte de assises durante o Segundo Império, Luc Passion percebe a rápida transferência dos velhos bairros do centro para os distritos mais excêntricos, em especial o décimo-oitavo e o décimo-nono. ${ }^{60} \mathrm{~A}$ análise dos domicílios daqueles condenados pelo tribunal correcional por cometerem delitos durante os anos 1888-1894 sublinha igualmente a predominância dos bairros operários, dos grandes Carrières até Charonne, bem como na parte sul da cidade, entre Grenelle e Bercy ${ }^{61}$ A esses dados sociológicos juntam-se elementos de natureza mais topográfica. Apesar dos decretos imperiais que, em novembro de 1853 e depois em dezembro de 1859, reformam e reorganizam a polícia; os bairros periféricos e os subúrbios sofrem de um evidente subenquadramento, de modo que a parte alta do vigésimo distrito padece de insegurança por muito tempo devido à ausência de um comissariado. ${ }^{62}$ Mesmo durante a Belle Époque, a denúncia de insuficiência policial nos subúrbios alimenta os discursos sobre segurança. Construçóes, terrenos baldios e espaços suspeitos nas margens da cidade favorecem igualmente o exercício da violência. É nesse cinturão sombrio que circula a cidade que se encontram os fait divers mais sanguinários: estupros, ajustes de contas, "ataques noturnos". ${ }^{63}$ É nas valas das antigas muralhas da cidade que são descobertos cadáveres ou detritos macabros; é um pouco mais longe que, ao longo do Segundo Império, ressoam os grandes crimes, como aqueles de Troppmann, na planície de Pantin, ou aquele menos conhecido de Jean Charles que estupra, mata e degola o contramestre Duguet, encontrado em junho de 1867 no marché de la Chapelle. O assassino morava nas redondezas e a morte ocorreu numa casa isolada de Levallois-Perret ${ }^{64}$

\footnotetext{
${ }^{58}$ Ver GAILLARD, Jeanne. Paris, la Ville. 1852-1879. Paris: L'Harmattan, 1999, p. 16 e ss.

${ }^{59}$ Ver especialmente: MERRIMAN, John. The margins of city life, op. cit.

${ }^{60}$ PASSION, Luc. Conjoncture et géographie du crime à Paris sous le Second Empire. Fédération des Sociétés Historiques et Archéologiques de Paris et de l'Ilê de France, 1982. p. 187-224.

* Jurisdição departamental francesa encarregada de julgar pessoas acusadas de haver cometido um crime. (N.T.)

${ }^{61}$ DEMIER, Francis; FARCY, Jean-Claude. Regards sur la délinquance parisienne à la fin du XIXe siècle. Rapport de recherche sur le jugements du tribunal correctionnel de la Seine (1888-1894). Université Paris X, 1997. p. 38-42.

${ }^{62}$ LAZARE, Louis. La France et Paris. Paris: Publications Administratives, 1872.

${ }^{63}$ KALIFA, Dominique. L'attaque nocturne. Sociétés \& Représentations, n. 4, p. 121-138, 1997.

${ }^{64}$ Archives de Paris, D2U8/7.
} 
Em processo de diminuição nos velhos bairros do centro, as violências noturnas se multiplicavam, por outro lado, nos distritos periféricos, após 1860 (sobretudo nos décimo quinto e vigésimo distritos, novos locais de degola), e na parte oriental da cidade que totalizava então mais de $62 \%$ das agressões. ${ }^{65}$ As ruas Botzaris, des Plâtiers ou de la Mouzzaia são frequentes teatros de fait divers sangrentos e a violência dos jovens é famosa em Belleville, onde nascem os Apaches na primavera de $1900 .{ }^{66}$ É em Charonne, entre la Courtille e les Orteaux que estoura, em 1902, o caso Casque d'or. Percebe-se o mesmo cenário em relação aos roubos (simples ou qualificados), que diminuem de 25 a $16 \%$ nos quatro distritos que formam o centro da cidade, entre a primeira e a segunda década do Segundo Império, em benefício da margem esquerda (rive gauche) e, sobretudo, dos bairros periféricos. ${ }^{67}$ As infraçóes cometidas fora dos limites administrativos da cidade aumentam também, acima de $12 \%$ do total nos anos 1890, especialmente no perímetro Saint-Ouen, Sant-Denis, Bagnolet, bem como em direção ao sudeste de Paris. ${ }^{68}$ Em muitos aspectos, portanto, a haussmannização do crime segue a haussmannização da cidade.

Mas esse movimento não impede que certas partes da velha Paris continuem perigosas. A expulsão dos populares do centro náo obteve efeito nem imediato nem sistemático, e essa região da cidade continuou a atrair, devido à concentração de certas atividades fundamentais (Les Halles, o grande mercado da capital, ficava nesta regiáo), toda uma sorte de pequenos profissionais de renda precária. Assim, os bairros de Saint-Merri, Saint-Gervais, os entornos da Sorbonne ou de la Halle aux vins forneciam frequentemente seu contingente de réus aos tribunais correcionais de la Seine. ${ }^{69} \mathrm{E}$ é aqui que registramos igualmente a mais forte densidade de hotéis e espeluncas populares e, apesar dos fechamentos operados por Haussmann, um grande número de bares ${ }^{70}$ locais de bailes e guinguettes. ${ }^{*}$ Mas é sobretudo devido à existência de uma densa rede de débitos de bebidas (o fiado), cuja cartografia se superpóe estreitamente àquela do crime, que se pode explicar a perenidade dos velhos bairros do centro. Era impossível de fato, para tais estabelecimentos, se passarem por bistrôs de Halles, únicos a se beneficiar de um privilégio administrativo que os autorizava a abrir durante toda a noite. Ao anoitecer, prostitutas e proxenetas deixavam a periferia para tomar seus lugares no coração da cidade. Por volta de 1900, a delinquência mais visível permane-

\footnotetext{
${ }^{65}$ DELATTRE, Simone. Les douze heures noires, op. cit. p. 358-359 e p. 517-518.

${ }^{66}$ JACQUEMENT, Gérard. La violence à Belleville au début du XXe siècle. Bulletin de la Societé d'Histoire de Paris et d'Ilê-de-France, p. 141-167, 1978. Ver também: KALIFA, Dominique. L'encre et le sang, op. cit. p. 152-164.

${ }^{67}$ CARBONNEL, Chantal. Les lieux du crime à Paris sous le Second Empire. Mestrado (história) - Université Paris VII, 2001.

${ }^{68}$ Regards sur la délinquance parisienne, op. cit, p. 36-38.

${ }^{69}$ Ibid.

${ }^{70}$ GASNAULT, François. Guinguettes et lorettes. Bals publiques à Paris au XXe siècle. Paris: Aubier, 1986.

* Estabelecimentos populares de Paris que poderiam servir como restaurante e local de bailes, mas realmente especializados na oferta de bebidas alcoólicas. Locais de lazer popular. (N.T.)
} 
cia sempre localizada no centro da cidade: bairro des Halles, especialmente no entorno da praça des Innocents ou do Sébasto', Palais-Royal, Saint-Gervais e, na margem esquerda, os bairros de la Maub' ou de la Mouff'. Se o caso do Casque d'or ' estoura em Charonne, é no lugar denominado Contrescarpe que a prostituta Amelie encontrou Manda e é no lugar l'Ange Gabriel, nos Halles, que a trama se estabeleceu. Em janeiro de 1910, o caso Liabeuf - o assassinato de um policial pelo sapateiro Liabeuf - fez da rua Aubry-le-boucher um símbolo desta Paris-Apache. As cartas endereçadas para a prefeitura (em 1882 quando instalavam os alertas sonoros e em 1912-1913 por ocasião dos projetos de reorganização dos serviços) ${ }^{71}$ revelam esta dupla localização do risco criminal: a periferia operária da cidade bem como o bairro de Halles ou a praça Maubert.

A estes fatores externos somam-se as restriçóes e críticas editoriais e literárias próprias da representação do crime, cujo jogo converge para preservar a imagem tradicional da Cité. O princípio de nostalgia em relação a esse lugar é particularmente ativo. Os últimos trinta anos do século XIX foram marcados pela multiplicação de obras pitorescas, assinadas por cronistas, repórteres e autores de folhetins que se queixam longamente sobre a Paris que desaparece.$^{72}$ Como as imagens de Marville (1858-1878), milhares de páginas se empenham em agrupar os vestígios reais e fantasiosos da capital. Um gênero se instala, com seu estilo e seus autores, onde a mediação sobre a perda se conjugava ao problema do pitoresco e à propensão para a lamentação. Emana a certeza da existência de uma outra cidade, indestrutível, inalterável. "Paris muda! Mas nada na minha melancolia/ Mudou! Novos palácios, andaimes, blocos,/ Velhas periferias, tudo se torna alegórico pra mim./ E minhas prezadas lembranças são mais pesadas que rochas", escreveu Charles Baudelaire em um poema (Le cygne) que ele dedicou a Victor Hugo em 1859.

Essas variaçóes sobre o desaparecimento se revelam assim mais produtivas do que aquelas que fazem concessão às necessidades específicas do texto "popular". Este é, de fato, regido pelo princípio da "repetição", 73 que opera ao mesmo tempo sobre os planos narrativos, temáticos e ideológicos. Para os autores obrigados a publicar muito e rápido, escrever é sempre reescrever, ainda mais com um estoque limitado de modelos e esquemas. ${ }^{74} \mathrm{~A}$ imagem da

\footnotetext{
* Personagens do filme francês Casque d'or, de 1952, dirigido por Jacques Becker. A história gira em torno do triângulo amoroso entre a prostituta Amélie Élie e os líderes Manda e Leca, da gangue Apache. (N.T.)

${ }^{71}$ APP/DB38; APP/DB35.

${ }^{72}$ VIRMAÎTRE, Charles. Paris qui s'efface. Paris: Savine, 1887. Alguns títulos entre muitos outros: COLL. Paris qui s'en va. Paris: Cadart, 1859; DE PENE, Henri. Paris mystérieux. Paris: Dentu, 1861; VIRMAÎTRE, Charles. Paris oublié. Paris: Dentu, 1866; VIRMAÎTRE, Charles. Les curiosités de Paris. Paris: Lebigre-Duquesne, 1868; ANONYME. Paris nouveau jugé par un flâneur. Paris: Dentu, 1868; GRISON, George. Paris horrible et Paris original, op. cit.; BELLON, Paul; PRICE, Geroges. Paris que passe. Paris: Savine, 1883.

${ }^{73}$ NATHAN, Michel. Le ressassement, ou ce que peut le roman populaire. In: GUISE, René; NEUSCHÄFER, Hans-Jörg (Dir.). Richesses du romain populaire. Nancy: Centre de recherchers sur le roman populaire, 1986. p. $235-250$.

${ }^{74}$ Ver os trabalhos de Jean-Claude Vareille, especialmente L'homme masqué, le justicier et le détective. Lyon: Press Universitaires de Lyon, 1989; e Le Roman populaire français (1789-1914). Idéologies et pratiques. Li-
} 
Cité criminal é deles. Esse fenômeno se acentua profundamente durante a segunda metade do século XIX, sob o efeito de uma crescente demanda de jornais, de editores e de público. Resulta daí um imenso intertexto, cuja repetição junta simultaneamente uma cultura e uma comunidade de leitores.

A isto se soma a incapacidade frequente do romance de folhetim de se desprender do imaginário romântico. Nascido em 1836, em um momento onde a divisão entre literatura legítima/literatura popular estava ainda apenas em gestação, este aproveitador do romantismo permanece muito ligado a este momento onde a indignidade náo se prendia a suas páginas. Mas o romantismo pesa também pelos seus temas e motivos, a começar pelo tema da cidade. É no século XIX que se inventa, de fato, o olhar sobre a cidade: aquele nascido da literatura, como espaço, como personagem, como texto. ${ }^{75}$ Para Balzac, por exemplo, a cidade não é um simples elemento decorativo, ela tem uma personalidade que envolve o romance e a vida. "As ruas de Paris possuem qualidades humanas, e nos revelam por sua fisionomia certas ideias contra as quais nós não possuímos defesa”, escreveu ele na obra Ferragus. ${ }^{76} \mathrm{O}$ contexto médico, dominado entâo pelo neo-hipocratismo, acentua essa tendência: os lugares têm "temperamentos" que atribuem atividades e controlam os tipos sociais; asseguram as topografias médicas que se multiplicam nessa mesma época. Estudando a prostituição parisiense nos anos 1830, Alexandre Parent-Duchâtelet conclui que "é dos negócios específicos de certos bairros (...) que vivem da reputação que foram transmitidas a todos aqueles que as têm mantido". ${ }^{77}$ As coisas se tornam evidentemente diferentes após 1850, onde prevalece o ideal de circulação, mas a estética folhetinesca sofre em extrair as representaçôes geradas no primeiro século XIX. Numerosos são aqueles que transportam a Monarquia de Julho para a Terceira República, reiterando as causas célebres ${ }^{78}$ ou algum "mistério da velha Paris"79 que repetem as mesmas imagens do submundo e dos barracos. Esta é a situação, por exemplo, de L'affaire de la rue du Temple de Constant Guéroult, que traz à tona em 1880 um crime célebre de 1836. No coração deste sistema irradia Les mystères de Paris, texto mítico e fundador que constitui um tipo de matriz ilimitada, reativada sem cessar não apenas nas reediçôes que se sucedem, fazendo com que este romance não conheça jamais o ocaso: 14 ediçóes ao longo da vida de E. Sue, que morre em 1857, e 19 reediçóes a partir desta data até 1914, frequentemente em coleçôes de grande tiragens (Rouff, Fayard), sem contar os periódicos departamentais, as adaptações teatrais, as cançôes etc. Mas esse romance suscita também

moges: Presses Universitaires de Limoges, 1994.

${ }^{75}$ HAMON, Philippe. Voir la ville. Romantisme, n. 83, p. 5-7, 1994. Ver também STIERLE, Karlheinz. La capitale des signes. Paris et son discours. Paris: Éd. de la MSH, 1993.

${ }^{76}$ BALZAC, Honoré. Histoire des treize [1833]. Paris: Albin Michel, 1953. p. 9.

77 PARENT-DUCHÂTELET, Alexandre. De la prostituition dans la ville de Paris, considéréé sous le rapport de l'hygiène publique, de la morale et de l'administration. Paris: Baillière, 1836. 2 v. Ver também o comentário proposto por Alain Corbin: Prostituition à Paris au XIXe siècle. Paris: Le Seuil, 1981. p. 9-15.

${ }^{78}$ LABOURIEU, Théodore. Lacenaire, le tueur de femmes. Paris: Rouff, 1885.

${ }^{79}$ PONT-JEST, René de. Sang maudit. Paris: Librarie Nationale, s.d. [1880]. Prologue. 
uma quantidade enorme de imitaçóes, de avatares, de plágios (Vrais mystères de Paris, Mystères du vieux Paris, Nouveaux mystères de Paris, Mystères du nouveau Paris etc.), ${ }^{80}$ de paródias (Les mystères de Passy) ${ }^{81}$ ou de séries paralelas (Les drames de Paris, de Ponsol du Terrail; Les tragédies de Paris, de Xavier de Montépin). ${ }^{82}$ Nesse sentido, cabe uma questão: sua estética e seu imaginário dominavam a tal ponto a sensibilidade folhetinesca do século que era difícil para os autores não reescreverem incansavelmente Les mystères de Paris?

Do romantismo, estas imagens da Paris criminal herdam ainda o gosto da Idade Média. ${ }^{83}$ Por que a cidade do crime representada pelos romancistas e cronistas populares deve muito àquela reinventada por Hugo, Dumas, Féval e outros. Eles tomam emprestado um estilo, especialmente aquele das cidades góticas, seus labirintos de becos, bem como seus "Tribunais de Milagres", mas também tomam uma parte de seus personagens e de suas referências criminais. "é o reino de Argot da Idade Média, modificado, alterado e corrigido de acordo com as exigências do progresso moderno", escreveu um romancista para apresentar "exército itinerante" dos anos $1880 .{ }^{84}$ A cidade medieval impóe igualmente sua estrutura em muitos folhetins: suas ruelas, seus labirintos, seus trocadilhos moldando os contornos da história, controlando sua narrativa intercalada, seus enredos, seus setores e seus impasses sucessivos. Procurando apresentar um "mundo especial” e muitas vezes atemporal do crime ou da delinquência, os folhetinistas revivem assim a cidade gótica, sua topografia e seu imaginário.

Mas esses textos são governados também pelas lógicas sociais que os atravessam. $\mathrm{O}$ romance criminal supóe geralmente uma sociologia simplificada, polarizada aos extremos para melhor opor as elites e os inferiores; a Paris aristocrática e aquela do submundo. Altamente produtiva no plano do romance, tal oposição exige, entretanto, uma topografia adaptada; e é por isso que transitamos tão frequentemente da opulência dos belos bairros ao pavor gerado pelas imagens do submundo. Nada melhor para evocar esse horror do que mergulhar o mais profundo possível nas representações: esta será então a Cité, seus cortiços ou o que resta deles; melhor ainda a Paris de ponta-cabeça, oculta, a Paris subterrânea das grutas e das catacumbas.

Objeto de tantas inquietudes, de fantasmas e de investimentos diferentes, a Paris do crime não poderia ser unívoca, e parte dessas imagens vistas aqui não esgotam a complexidade do fenômeno. Elas indicam, no entanto, um quadro que se manteve estranhamente estável

\footnotetext{
${ }^{80}$ Ver o ensaio de René Guise por ocasião do aniversário de 150 anos do Les mystères de Paris. Bulletin des amis du roman populaire, n. 17, 1992.

${ }^{81}$ Parodie-vaudeville en onze tableaux, cinq actes, avec prologue et épilogue, par MM. Rochefort et Dartois. Paris, 5 mars 1844.

${ }^{82}$ PONSON DU TERRAIL, Alexandre. Les drames de Paris (1857-1870), rapidamente seguido por Nouveau drames de Paris de Hippolyte Ruy. Paris: Lambert et Compaigne, s.d.; MONTEPIN, Xavier de. Les tragédies de Paris. Paris: Librarie Sartorius, 1874-1875. 4 v.

${ }^{83}$ AMALVI, Christian. Le gồt du Moyen Age. Paris: Plon, 1994; DURAND-LEGUERN, Isabelle. Le Moyen Age des romantiques. Rennes: Presses Universitaires de Rennes, 2001.

${ }^{84}$ AIMARD, Gustave. Les peaux-ronges de Paris, op. cit. p. 289.
} 
ao longo do século XIX. Se outros lugares, como os Estados Unidos, aumentaram sua influência sobre a imaginação criminosa, Paris assegurou seu lugar. Suas margens de delinquentes recuaram ainda mais para aquelas cidades que estão agora nas longínquas periferias, mas seu centro, que não conseguiu se desfazer do topônimo anacrônico de "Halles", conservou toda sua carga transgressora. E é na conjunção desses dois espaços, ambos cada vez mais americanizados, que reside em larga medida a insegurança contemporânea.

No entanto, além da história de Paris, este exemplo também se aplica para aqueles das representaçôes, notadamente as literárias. O material "popular" mobilizado aqui se revela especialmente por meio do confronto de dois princípios de escrita, portadores de duas concepçôes de mundo, de dois sistemas simbólicos de fato. ${ }^{85}$ De um lado, a nostalgia chamada por Lukács de a civilizaçáo dos bordéis, o conjunto de temas imutáveis que expressam uma espécie de devaneio regressivo ou épico. De outro, a atenção à modernidade, à mudança, ao pensamento historicista que o suporte jornalístico e editorial materializa no cotidiano e que as vicissitudes ou a documentação realista refletem na ordem da narrativa. Constantemente dividida entre topografias opostas, a Paris do crime expóe muito bem esta tensão interna própria do texto popular. Será que isso significa que a literatura popular é de pouca utilidade para o historiador, ansioso em discernir primeiro as transformaçóes sociais? Nada mais falso do que isso, na medida em que esses textos, como qualquer ficção, são úteis também para pensar a experiência, evidenciando as avaliaçóes e os comportamentos. Tanto para o grande público, que pode encontrar ou não a confirmaçáo de suas inquietudes nos textos literários, quanto para a sociedade delinquente à qual fornece referências, modelos ou uma história, as ficçôes são totalmente constituídas pelos desenvolvimentos sociais. À condição talvez de serem consideradas uma outra fonte, que cruza os conteúdos manifestos com aqueles dos regimes de produção, dos sistemas de restrições, de intençôes que lhe são próprios e que modelam profundamente suas representaçóes.

\footnotetext{
${ }^{85}$ Retomo aqui as análises penetrantes de Jean-Claude Vareille. Le roman populaire français, op. cit.
} 